\title{
Corrigendum to "Formation and erosion of the seasonal thermocline in the Kuroshio Extension Recirculation gyre” [Deep-Sea Res. II 85 (2013)
} $62-74]$

\author{
Meghan F. Cronin ${ }^{\mathrm{a}, *}$, Nicholas A. Bond ${ }^{\mathrm{b}}$, J. Thomas Farrar ${ }^{\mathrm{c}}$, Hiroshi Ichikawa ${ }^{\mathrm{d}}$, \\ Steven R. Jayne ${ }^{\mathrm{c}}$, Yoshimi Kawai ${ }^{\mathrm{d}}$, Masanori Konda ${ }^{\mathrm{d}, \mathrm{e}}$, Bo Qiu ${ }^{\mathrm{f}}$, Luc Rainville ${ }^{\mathrm{g}}$, \\ Hiroyuki Tomita ${ }^{\mathrm{h}}$ \\ a NOAA Pacific Marine Environmental Laboratory, 7600 Sand Point Way NE, Seattle, WA 98115, USA \\ ${ }^{\mathrm{b}}$ University of Washington/NOAA Joint Institute for the Study of Atmosphere and Ocean, 7600 Sand Point Way NE, Seattle, WA 98115, USA \\ ${ }^{\mathrm{c}}$ Woods Hole Oceanographic Institution, 266 Woods Hole Road, Woods Hole, MA 02543, USA \\ d Japan Agency for Marine and Earth Science Technology, Research and Development Center for Global Change, Yokosuka, Kanagawa 237-0061, Japan \\ e Kyoto University, Graduate School of Science, Kitashirakawa-Oiwake, Sakyo, Kyoto 606-8502, Japan \\ ${ }^{\mathrm{f}}$ University of Hawaii, School of Ocean and Earth Science and Technology, 1000 Pope Rd, Honolulu, HI 96822, USA \\ ${ }^{\mathrm{g}}$ University of Washington/Applied Physics Laboratory, 1013 NE 40th Street, Seattle, WA 98105, USA \\ ${ }^{\mathrm{h}}$ Institute for Space-Earth Environmental Research, Nagoya University, Nagoya, Japan
}

The authors regret that Fig. 8 bottom panel had a 0.1 offset applied to the buoyancy frequency $(N)$. This plotting error did not affect any other aspect of the original paper. The correctly plotted Fig. 8 is shown below.

\footnotetext{
DOI of original article: http://dx.doi.org/10.1016/j.dsr2.2012.07.018

* Corresponding author. Fax: +1 2065266744

E-mail address: Meghan.F.Cronin@noaa.gov (M.F. Cronin).
} 

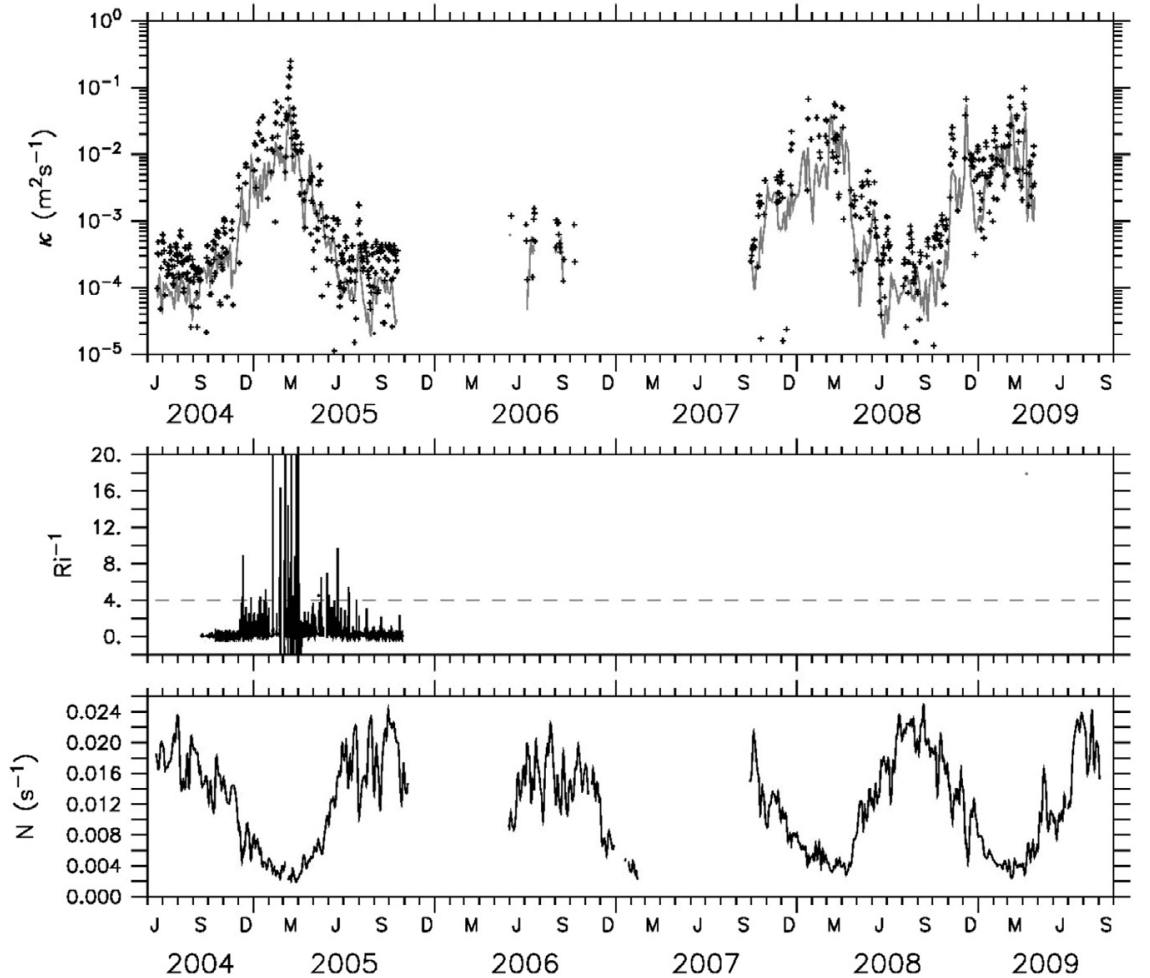

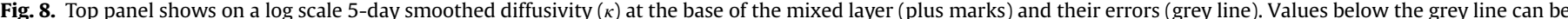

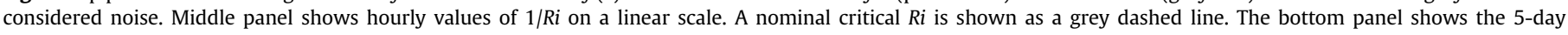
smoothed buoyancy frequency $(N)$ on a linear scale. 